CAMBRTge: PRINTED BX W. LEWIS, M.A.

AT THE UNIVERSTTY PRESS 


\section{Proceedings of the CAMBRIDGE PHILOSOPHICAL SOCIETY}




\section{CAMBRIDGE \\ UNIVERSITY PRESS \\ LONDON：BENTLEY HOUSE \\ BOMBAY CALCUTTA MADRAS \\ Macmillan}

$\Delta a$ rights reserved 


\section{Proceedings of the}

\section{CAMBRIDGE PHILOSOPHICAL SOCIETY}

VOLUME 38

CAMBRIDGE

AT THE UNIVERSITY PRESS

1942 
PRINTED IN GREAT BRITATN 


\section{CONTENTS}

Besicovitch, A. S. Relations between concentrated sets and sets possessing property $\mathbf{C}$

A. theorem on s-dimensional measure of sets of points

Born, M. On the stability of crystal lattices. IX. Covariant theory of lattice deformations and the stability of some hexagonal lattices. (With 2 Figures in the Text)

Coulson, C. A. Two-centre integrails occurring in the theory of molecular structure .

Coulson, C. A. and Duncanson, W. E. Momentum dístribution in molecular systems. Part VI. Shape of the Compton line for methane $\mathrm{CH}_{4}$. (With 4 Figures in the Text)

Dirac, P. A. M., Pelerls, R. and Pryce, M. H. L. On Lorentz invariance in the quantum theory

Duncanson, W. E. and Coulson, C. A. Momentium distribution in molecular systems. Part VI. Shape of the Compton line for methane $\mathrm{CH}_{4}$. (With 4 Figures in the Text)

Eddington, Sir Arthur. On Lorentz invariance in the quantum theory. II

Edmonds, Sheila M. On the Parseval formulae for Fourier transforms . . . . .

Erdélyi, A. On certain expansions of the solutions of Mathieu's differential equation $\quad 28$

On certain expansions of the solutions of the general Lamé equation . . . $\quad$ - 364

Friedlander, F. G. On the solutions of the wave equation with discontinuous de. rivatives

On the reflexion of a spherical sound pulse by a parabolic mirror .

Note on a limit related to the curvatures of two surfaces

Good, I. J. Some relations between certain methods of summation of infinite series. (With I Figure in the Text)

Grundy, P. M. A generalization of additive ideal theory

Heitler, W. and Peng, H. W. The influence of radiation damping on the scattering of mesons. II. Multiple processes

Hodge, W. V. D. A note on $k$-connexes

- Note on the degeneration of algebraic varieties

Jeffreys, Bertha. Note on an anomaly in the spectrum of $\mathrm{O}^{++} \quad$ - $\quad . \quad$. $\quad$ • $\quad 290$

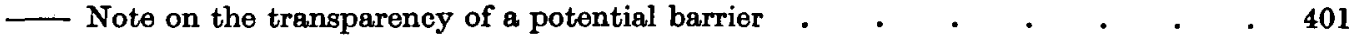

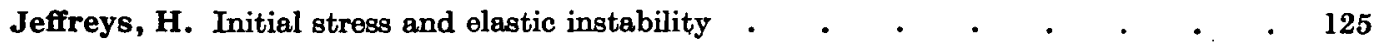

Littlewood, D. E. On the number of terms in a simple algebraic form . $\quad$ • $\quad$ • 394

Mathisson, M. Relativistic dynamics of a spinning magnetic particle . . $\quad$. $\quad$. 40

Miller, A. R. The number of configurations of a cooperative assembly. (With 8 Figures in the Text)

Orr, W. J. C. Expansions for a particular class of exponential-logarithmic integrals . 
Pedoe, D. A remark on a property of a special pencil of quadrics

An inequality for two triangles

Peierls, R., Dirac, P. A. M. and Pryce, M. H. L. On Lorentz invariance in the quantum theory

Peng, H-W. and Heitler, W. The influence of radiation damping on the scattering of mesons. II. Multiple processes

Peng, H. W. and Power, S. C. On the stability of crystal lattices. VIII. Stability of rhombohedral Bravais lattices. (With I Figure in the Text)

Pitt, H. R. Some generalizations of the ergodic theorem

Power, S. G. On the stability of crystal lattices. VII. Long-wave and short-wave stability for the face-centred cubic lattice

Power, S. G. and Peng, H. W. On the stability of crystal lattices. VIII. Stability of rhombohedral Bravais lattices. (With 1 Figure in the Text) . . . .

Pryce, M. H. L., Dirac, P. A. M. and Peierls, R. On Lorentz invariance in the quantum theory

Rogosinski, W. W. On Hausdorff's methods of summability

On Hausdorff's methods of summability. II

Rushbrooke, G. S. The thermodynamic derivation of Fowler's adsorption isotherm

Sedgwick, W. F. On the theory of successive radioactive transformations

Segre, B. The postulation of a multiple curve

Stokes, A. R. and Wilson, A. J. C. A method of calculating the integral breadths of Debye-Scherrer lines

Watson, G. N. An infinite integral

Wilson, A. J. C. and Stokes, A. R. A method of calculating the integral breadths of Debye-Scherrer lines

Proceedingó .

Batiance Shemet 


\section{The Indian Mathematician \\ R A M A N U JA N}

Twelve lectures on subjects suggested by his life and work

$$
\text { By G. H. HARDY }
$$

\section{With a frontispiece portrait. $27 s .6 d$. net}

Ramanujan worked for most of his short life in almost complete ignorance of modern European mathematics, yet before his death at a little over thirty, when his mathematical education had hardly begun, he had become a Fellow of the Royal Society. This book, by his discoverer, is a study of the work and life of the young Indian-the most romantic figure in the recent history of mathematics.

\section{THE THEORY AND APPLICATIONS OF HARMONIC INTEGRALS}

\section{By W. V. D. HODGE}

\section{Is. net}

The subject of this book is the study of certain integrals defined by a type of space of importance in various branches of geometry-locally the space of Riemannian geometry, in large, an orientable manifold. In his early chapters Professor Hodge includes chapters on the geometry of space in which the integrals are defined; the properties of integrals on a manifold; and an introduction to harmonic integrals. The remainder of the book is concerned with the applications of the theory of harmonic integrals to other branches of mathematics.

\section{THE CALCULUS OF EXTENSION \\ By HENRY GEORGE FORDER

$$
3 \text { Is. } 6 d \text {. net }
$$

Grassman's Calculus of Extension is an abstract algebra with a wide range of applications; this book is mainly concerned with its use in Geometry. In the method of this book, equations are used involving the geometric entities themselves, such as points, lines, circles, or quadrics, and not their co-ordinates; to prove a geometric theorem is to prove such an equation, and as in most cases the equation turns out to be an identity, this gives an automatic method for proving geometric theorems. The book includes a treatment of matrices in the service of geometry.

\section{CAMBRIDGE UNIVERSITY PRESS}




\section{CONTENTS}

PAGE

Piтt, H. R. Some generalizations of the ergodic theorem . . . . 325

Rogosinski, W. W. On Hausdorff's methods of summability. II . . 344

ERdélyi, A. On certain expansions of the solutions of the general Lamé equation . . . . . . . . . . . 364

SEgRe, B. The postulation of a multiple curve . $\quad$. . . . 368

Friedlander, F. G. On the solutions of the wave equation with discontinuous derivatives . $. \quad . \quad . \quad . \quad . \quad . \quad . \quad .378$

Friedlander, F. G. On the reflexion of a spherical sound pulse by a parabolic mirror $\quad . \quad . \quad . \quad . \quad . \quad . \quad . \quad . \quad . \quad 383$

LitTlewood, D. E. On the number of terms in a simple algebraic form . 394

Research Notes:

Pedoe, D. An inequality for two triangles . . . . . . 397

Friedlander, F. G. Note on a limit related to the curvatures of two surfaces . . . . . . . . . . . 399

JEFFREYS, Bertha. Note on the transparency of a potential barrier . 401

Proceedings.

Balance Sheet $. \quad . \quad . \quad . \quad . \quad . \quad . \quad . \quad . \quad . \quad .408$

\section{LONDON: CAMBRIDGE UNIVERSITY PRESS}

INDIA: MACMILLAN

PRINTED IN GREAT BRITAIN BY W. LEWIS, M.A., AT THE UNIVERSITY PRESS, CAMBRIDGE

DUTCH REPRINT 